\title{
Research and Practice on School-enterprise Collaborative Talent Cultivation Mode in Higher Vocational Colleges
}

\author{
Chen Zhou, Lantao You, Ying Gao \\ Suzhou Industrial Park Institute of Services Outsourcing \\ Suzhou, Jiangsu, 215213, China
}

\author{
Fangmei Ning \\ Suzhou Centennial College \\ Suzhou, Jiangsu, 215213, China
}

\begin{abstract}
A major demand for colleges education is to improve the cultivation quality of higher vocational talents, but for higher education in our country, the major task is to fully combine forces of colleges, government and the society (enterprises), and build innovation and entrepreneurial talent cultivation system for college students. Synergetic theory is an emerging discipline that is gradually formed and developed on the basis of studying system theory, control theory, information theory and other modernized and scientific achievements. The school-enterprise collaborative talent cultivation mode based on synergetic principle is an effective mode, and the main approach to cultivate software technical talents is to adopt joint project development. By adopting theoretical analysis on schoolenterprise collaborative talent cultivation, this paper finds out that, under current conditions, joint project development mode is a cooperation mode that can be accepted by all parties. By combining relevant practical results, this paper has drawn the conclusion that this method is the most effective one.
\end{abstract}

Keywords-synergetic principle; school-enterprise collaboration; software talent cultivation; joint project development

\section{INTRODUCTION}

In the Second Session of 13th NPC, Premier Keqiang LI Further pointed out in the government report that, "we should accelerate the development of modernized vocational education, which can alleviate current employment pressure, and solve the shortage of high-skill talents." "We should accelerate the cultivation of technical skill talents requested for national development by the reform and development of modernized vocational education", and make us realize the importance and expectations of the state for higher vocational education.

Higher vocational education has the dual attributes of higher education and vocational education, and is aimed to cultivate high-qualified and practical technical talents with solid theoretical foundations and skillful operational technologies required by the society. Based on this objective, it has decided that we must adopt the alternative mode of classroom teaching and practical teaching based on production practice. Meanwhile, "practicability" in practical talents has decided the course system that shall be set mainly on the basis of enterprise demands, and the talent cultivation that adopts

This paper is one of the research achievements of the Teaching Reform Topic of Suzhou Industrial Park Institute of Services Outsourcing (JG-201708, JG201905) and the Research Topic of Suzhou Higher Vocational Education and Teaching Reform (SGJGA0117). "order-type" cultivation mode oriented to enterprise demands.

As specified in National Outline for Medium and Longterm Educational Reform and Development Plan (2010-2020): "To implement the talent cultivation mode of work-integrated learning, school-enterprise cooperation, and post practice, establish sound government-led, industrial-guided and enterprise-participated school-running mechanism, formulate school-running regulations that promote school-enterprise cooperation, and promote school-enterprise cooperation institutionalization." [1] "The outline" has not only specified the position of school-enterprise cooperation talent cultivation mode in modernized vocational education system, but also puts forward clear requirements for talent cultivation mechanism in school-enterprise cooperation.

School-enterprise cooperation refers to a mutual cooperation mode established by colleges and enterprises. It can cultivate talents for enterprises with target as per the characteristic demand of enterprises. It emphasizes on the practicability and effectiveness of talent cultivation, and is a three-party multi-win mode of schools, students and enterprises that focuses on the cultivation quality by combining school study and enterprise practice as well as the resource and information sharing of schools and enterprises.

\section{CHARACTERISTICS OF SOFTWARE SPECIALTY}

Software technology specialty is a practical and creative industry. Software development and relevant peripheral work are quite demanding in the professional knowledge of employees, their logic analysis and actual operation capacity.

But the talent target of higher vocational colleges is to cultivate applied software talents, and emphasize more on cultivating the actual application capacity, when comparing with undergraduate universities. Collaboration with relevant enterprises is the necessary means for professional software construction and development, student cultivation and knowledge acquisition.

It is mainly reflected in the following two aspects: Firstly, it is to cooperate with the enterprise based on industrial development demands, and build course systems and capacity target meeting market demands; Secondly, it is to introduce enterprise resources, and intervene comprehensively in the 
entire education and cultivation process of students, make students apply what they have learned, and help enterprises cultivate and select the talent they need, then realize the best win-win effect between schools and enterprises.

\section{ABROAD SITUATIONS}

Modernized higher vocational education is started from Europe, such as Germany Dual System, French Modern Apprenticeship System, British Sandwich System. Other developed economics have also been valued and developed into different modes based on their own conditions, such as American cooperation education, and Singapore "teaching factory". School-enterprise collaborative talent cultivation system has become a main trend of higher educational reform and development in main countries worldwide and the effective approach for combining education and industrial economics and cultivating innovative talents, and has obtained good practical effect in their respective countries and regions.

By comparing with relatively sound school-enterprise cooperation mode in foreign countries, such as Germany, we can analyze and conclude the problems in our schoolenterprise cooperation, which can be mainly reflected below: The time of practice at enterprises is extremely short, or even zero before junior year, which can do little to help improve students' practical skills; Few enterprises are enthusiastic about the cultivation of students, and some of them regard this as a burden; The degree of participation for construction enterprises on the school-enterprise cooperation platform has showed gradual decrease, and the follow-up school-enterprise cooperation platform is basically the unilateral teaching at schools.

Based on the practice conditions and investigation, we analyze and hold the main reasons causing this phenomenon as follows: Firstly, it is the difference of schools and enterprises in objectives. Colleges seek for the pertinence of academic investigation and the practicalness of talent cultivation, while enterprises seek for the utilization of human capital and the improvement of economic profits; Secondly, school-enterprise cooperation isn't deep enough, and cannot truly realize industry-education integration, or bring direct benefits to enterprises, so enterprises think that schoolenterprise cooperation is a burden; Thirdly, the cooperative mechanism for schools and enterprises isn't sound enough in specific work. From the perspective of schools, they lack in the experience to cooperate with enterprises and cannot cooperate with their demands; But for enterprises, it is also difficult to cooperate schools in management mechanism considering lots of aspects, including the formulation of evaluation mechanisms for intern tutors.

\section{SCHOOL-ENTERPRISE COLLABORATIVE TALENT CULTIVATION}

\section{A. Synergetic theory}

Synergetic theory is the emerging discipline that is gradually formed and developed on the basis of studying system theory, control theory, information theory and other modernized and scientific achievements. The main characteristics are as follows: It puts forward a unified world that includes not only micro simplicity, but also macro universality; and further points out that, material system operation in objective world has a "self-organization" collaborative operation mechanism. This enlightens us to consider two aspects when cultivating talents, i.e., Firstly, it is to give play to subject guided functions of colleges in the process. Secondly, it is to promote different objects to rely on each other, cooperate mutually, and jointly promote the growth of innovation and entrepreneurial talents by virtue of school-enterprise cooperation and school-government support.

\section{1) Self-organizing principle}

Synergetic theory puts forward that: A system that can obtain certain stable space-time and functional structure without relying on specific intervention outside. This system is self-organized, and is actually reflected in the capacity of maintaining system and generating new functions. The stronger the system self-organization is, the bigger the promoted synergistic effect between systems will be, to constantly realize a new stable status of the system.

\section{2) Control variable, control principle}

In the self-organization process of the system, all subsystems, parameters or factors inside can generate different influences on system status. When being away from the critical point of the system, this difference and unbalance will be restrained, but it won't be reflected; When the system interacts with external systems, internal control parameters will change, and when it approaches to the critical point, such difference and unbalance will be reflected, distinguish the influence degree of control parameters in return, find out the control variables exerting major influence or leading effect in the system, i.e., the slow variable. Therefore, when we face complicated and multivariable systems, we can divide it into a controllable system with few slow variables, to decrease system processing dimensions, which can be helpful to solve actual system problems.

\section{3) Order parameter principle}

Orders parameters refer to a type of special slow variables that are originated from internal system, grow out of nothing, and can indicate the formation of new structures in the process of system evolution. When the early system is under disorder structure state, order parameters cannot be formed and are hard to be recognized; When the system operation approaches to the critical point, all subsystems can form a cooperation relationship and order parameters can only be formed in collaborative actions; But once it is formed, order parameters will become the fore to master system evolution process, and also become certain slow variables mentioned in the control principle mentioned in the former section. In respect of the important role of order variables, by recognizing order 
variables in the system as soon as possible, it is of special importance for applying the basic theories of collaboration in studying and building professional and qualified talent cultivation system of software specialty.

Order parameter principle in synergetic theory indicates that, we should seek for sources in slow variables when building controllable systems, and then form the main controlled order parameters of new systems; However, as per control variable principle, slow variables cannot be directly recognized from visible control parameters, instead, it can only be reflected by constantly stimulating system operation, to reach to the critical point

This shows that, the visible control parameters in the recognition system can stimulate system operation to reach the critical point, and this can be the major conditions to build a collaborative and controllable new system.

School-enterprise collaboration requests us to make full use of the big support of the state, encourage higher vocational education under the foundation of school-enterprise cooperation. The government, schools and enterprises should fully cooperate, to ensure material supply for students, schools and teachers in expenditures, and equipment, etc. Besides, multiple motivation mechanisms will be set, such as schoolenterprise cooperation bonus, entrepreneurship and innovation rewards, competition rewards, and teaching reform rewards. Under sound evaluation system, it is aimed to finally realize the objective of cultivating qualified talents.

\section{B. School-enterprise collaborative talent cultivation mode for software specialty}

In respect of the contradictory prominent problems in applied software talent capacity demand and cultivation structure, it puts forward the construction of the software industry ecosphere cored by school-enterprise collaboration, and then implements the cultivation mode of applied software talents by the integration of production and education, collaborative development, mutual benefits and win-win result

Joint project development stars from project development, and by combining enterprise advantages in technologies, requirements and actual manipulative ability of project development, schools can make use of the advantages in teachers' theoretical knowledge and knowledge structure, and lead students to jointly participate in project development, and meet future enterprise employment requirements for students' knowledge structure and manipulative ability by joint development.

We put forward a cultivation mode cooperated by software specialty and enterprises that regards projects as the cooperation basis and is mainly used in practical training courses: In the fresh and junior year, enterprises will provide actual projects, jointly tailor with schools and generate actual training projects adapt to current teaching requirements. By jointly carrying out work, schools can get actual training materials and understand the current enterprise technology requirements and provide certain evidences to adjust course systems; in the junior year, enterprises will directly absorb partial students to enter internship positions.
Based on the model, we have provided system assurance: For teachers, school-enterprise work is included in the evaluation index, with corresponding requirements and encouragements; for enterprise engineers, except for cooperating carefully in work and studying with an open mind, our teachers are also provided with competitive subsidies for class fees.

\section{CURRENT PRACTICAL CONDITIONS}

As for schools, it is difficult to request enterprises to implement active reforms for problems encountered in schoolenterprise cooperation, and schools must adapt to the situation actively. The outsourcing institute where I am working at values school-enterprise cooperation and has formulated corresponding evaluation and motivation mechanism for close cooperation with enterprises, which include the following contents specifically: Cooperate with large and medium-sized enterprises, pioneering enterprises, and school enterprises in textbooks, enterprise part-time teachers, enterprise donation/scholarship, etc., and encourage teachers to act as the visiting engineer of enterprises, etc.

Under such policy, our software specialty has taken active measures to carry out eight types of joint construction modes, including the joint construction of specialty, order cultivation, mutual recruitment of teachers, joint construction of courses, textbooks, practical base, resource sharing, joint technical research with Auntec Co., Ltd., Suzhou Yunjike Software, As Computer Technology (Suzhou) Co., Ltd., etc. and has formed the school-enterprise collaborative system that regards talent cultivation as the core, scientific research as the bond, social service as the support and cultural inheritance as the element.

In practice process, we think that joint project development is the cooperation mode mostly recognized by the two parties. By joint project development, schools can understand the newest technical requirements of enterprises by cooperation, then guide the revision of course systems, and maintain the timeliness of course setup; Enterprises can make knowledge contents of professors at schools meet their own employment demands, while getting the first-hand information of students, so that they can select talents more conveniently. This mode has ensured the win-win situation of schools and enterprises.

Taking an example of our cooperation conditions with Auntec Co., Ltd., this can reflect that we have realized the three-win situation of schools, enterprises and students by indepth school-enterprise cooperation:

Founded in March 2015, Auntec Co., Ltd. is an innovative technology enterprise that is engaged in mobile internet+ shared economy. The company is located in Suzhou Industrial Park Creative Industry Park. It is engaged in responding to Chinese internet innovation strategies by shared economy practice, and has created a qualified technical skills sharing platform by making full use of the integration advantages of professional skill talent resources. It is mainly engaged in software development, data recovery, the operation of public account, etc. Since the establishment of the company, it has established good cooperation relationship with our software specialty in course construction, the settlement of enterprise engineers, and the beginning of courses, etc. Above 10 fresh 
graduates were enrolled into the company for practice in 2015 , and finally 6 people were employed. Up till present, the company has above 30 employees graduated from the university, and 3 of them are engaged in middle management work.

By cooperation, students' talent cultivation system has been verified, and a batch of graduates obtained satisfying work by cooperation, and the enterprise also obtained constant talent resources.

\section{CONCLUSION}

By above 5 years of cooperation with many software enterprises, we have obtained certain achievements in professional construction, and the specialty has been awarded as the provincial key construction specialty of demonstration construction, etc.

By joint project development, we will be engaged in school-enterprise collaborative talent cultivation and realize win-win result in schools, enterprises and students: The school has perfected the teaching system and met the teaching objective; the enterprise has obtained talents and saw profits; Students have learned knowledge and docked with future working units.

We are now expanding further cooperation with the enterprise, to further perfect the reform in school-enterprise collaborative talent cultivation and make further progress in education and teaching.

\section{REFERENCES}

[1] State Council. National Outline for Medium and Long-term Educational Reform and Development Plan (2010-2020) [Z]. 2010.

[2] Ying HE. Discussion about the School-enterprise Collaborative Cultivation Mode of Applied Talents in Local Colleges [J]. Journal of Tongren University, 2017 (08), 13-114.

[3] Kai DONG. Research about School-enterprise Cooperation and Teaching Management in Higher Vocational Colleges Based on Modern Apprenticeship System [J]. Western China Quality Education, 2018 (4): 232.

[4] H•Haken. Higher Synergetics[M]. Beijing: Science Press, 1989.

[5] Jian LIN. Cultivation of Excellent Engineer by School-enterprise Full-course Cooperation and Cultivation [J]. Research on Higher Education of Engineering, 2012 (5): 335.

[6] Yanrong FU. Synergetic Theory and Applied Research Summary[J]. Journal of Tianjin University of Technology and Education, 2015, 25 (01), 44-47.

[7] Tao JIN and Hongzhi JIA. Research about the Practical Teaching System of Innovative Engineering Talent Cultivation[J]. Education and Teaching Forum. 2016 (25)

[8] Johan Bruneel, Pablo D’Este, Ammon Salter. Investigating the factors that diminish the barriers to university - industry collaboration [J]. Research Policy,2010 (7)

[9] P. D'Este, P. Patel. University - industry linkages in the UK: What are the factors underlying the variety of interactions with industry? [J]. Research Policy,2007 (9)

[10] Xianglong XIAO. Research about School-enterprise Collaborative Development of Diversified Platform Based on Collaborative Theory[J]. Modern Education Management, 2014, (1): 39-42.

[11] Ye CAO. Defects in Three Mechanisms of School-enterprise Cooperation for Vocational Education in Our Country and the Solving Strategies [J]. Chinese Vocational and Technical Education, 2016 (18): 74-78.

[12] Xiaochun FAN, and Jiaxuan YANG. Case study about Collaborative Innovation Mode between Professional Groups and Small and Mediumsized Enterprises in Higher Vocational Colleges[J]. Journal of Educational Institute of Jilin Province, 2017 (05).

[13] Xiongwu ZHANG. Construction of Diversified Collaborative Cultivation Mechanism for Innovation and Entrepreneurial Talents in Colleges [J]. Journal of National Academy of Education Administration, 2016 (4): 30-37.

[14] Qinxiu SUN and Hanfeng GAO. Significance and Practice of Innovation and Entrepreneurship Education in Higher Vocational Colleges[J]. Innovation and Entrepreneurship Education, 2013 (4): 49-51.

[15] You LU, Xuefeng XI, Ze HUA et al. A Computer Practice Type Course Teaching Method Driven by Iterative Project Development [J]. University Education, 2013 (8): 55-56. 